\title{
Métodos de diagnóstico para deteç̧ão de prostatopatias caninas
}

\author{
Canine prostatic disease: diagnosis methods
}

Ceres Mussel ${ }^{\mathrm{I}}$ Francislete Rodrigues Melo $^{\mathrm{I}}$ Hélio Blume $^{\mathrm{I}}$ Fernanda Mulinari $^{\mathrm{I}}$

\section{- REVISÃO BIBLIOGRÁFICA -}

\section{RESUMO}

As doenças prostáticas são comuns em cães, desenvolvendo-se após a maturidade sexual. Entre as afecções que acometem a próstata desses animais, a mais frequente é a hiperplasia prostática benigna (HPB). As neoplasias prostáticas, apesar de menos frequentes, são altamente malignas e um diagnóstico tardio está associado a um prognóstico ruim. Os principais métodos de diagnóstico das enfermidades prostáticas em cães incluem um exame clínico detalhado, ultrassonografia, punção aspirativa e biópsia. A utilização de biomarcadores séricos vem sendo estudada como uma maneira de se detectar a doença precocemente, evitando possíveis complicações no quadro clínico dos pacientes. Assim, estudos visando ao diagnóstico precoce de prostatopatias caninas, especialmente o câncer prostático, são cruciais para um tratamento eficaz e melhora da qualidade de vida do animal acometido.

Palavras-chave: cão, próstata, $H P B$, câncer, métodos de diagnóstico.

\section{ABSTRACT \\ Prostatic diseases are common in older dogs, developing after sexual maturity. The most common affecting canine prostate is benign prostatic hyperplasia (BPH). Although less frequent, prostatic neoplasias are highly malignant, and a late diagnosis is closely associated with a poor prognosis. The main methods of diagnosis of the canine prostatic disease include a detailed clinical exam, ultrasound, prostatic fine- needle aspirate and biopsy. Studies towards early diagnosis of this condition are crucial for effective treatment and improvement of quality of life of affected animals. The use of biomarkers has been studied for early detection of the disease, avoiding possible complications in clinical patients.}

Key words: dog, prostate, BPH, cancer, diagnostic methods.

\section{INTRODUÇÃO}

O carcinoma prostático canino apresenta prevalência de 0.2 a $0,6 \%$ (WEAVER, 1981). É clinicamente agressivo e invasivo, provocando metástases para linfonodos ilíacos externos e internos ou plexos venosos, vertebral e sistêmico, para as vértebras e pulmões. É possível a ocorrência de metástase também para o coração, rins, mesentério e epíplon (Di SANTIS et al., 2001). Pode ainda disseminarse, invadindo bexiga e ureteres, assim como a musculatura da pelve e do cólon. O prognóstico ruim associado ao câncer prostático canino pode, em parte, ser atribuído ao diagnóstico tardio da afecção (SERAKIDES et al., 1997; WATERS \& BOSTWICK, 1997).

Os sinais clínicos das doenças da próstata são semelhantes e podem evoluir sem nenhum sinal clínico evidente ao proprietário do animal, dificultando a detecção precoce, o que, no caso de câncer prostático, pode ser fatal. (CORNELL et al., 2000). Devido à facilidade de execução, o exame ecográfico da próstata é muito utilizado para verificar alterações prostáticas, visto que permite caracterizar não somente o tamanho e o contorno prostático, como também o parênquima glandular e estruturas com fluidos em seu interior (CARTEE \& ROWLES, 1983). Porém, apesar da utilização da ultrassonografia para a avaliação do tecido prostático, a distinção entre as doenças prostáticas

'Departamento de Medicina Veterinária da União Pioneira de Integração Social, Distrito Federal, Brasília, Brasil. E-mail: ceres_mussel@yahoo.com.br.*Autor para correspondência 
não é possível somente com o uso desse exame (FEENEY et al., 1987; KAY et al., 1989).

A aspiração da próstata por agulha fina é descrita como uma maneira de se identificar as lesões observadas no exame sonográfico de forma segura, sem que ocorram complicações com o paciente. A biópsia é realizada para diagnosticar afecções que não foram conclusivas ao exame de citologia aspirativa ou para proporcionar um diagnóstico definitivo de adenocarcinoma (BARSANTI et al., 1980; BOLAND et al., 2003).

O uso de testes séricos para detectar as enfermidades desse órgão, especialmente as neoplasias malignas, poderá aumentar a sobrevida dos animais acometidos. Assim, o estudo de biomarcadores séricos em cães vem sendo explorado. Destacando-se aqueles utilizados em humanos, como o antígeno prostático específico (PSA) e a fosfatase ácida (PAP), bem como a esterase prostática secretória canina (CPSE), específica da próstata canina.

Esta revisão tem como objetivo reunir as informações a respeito dos métodos de diagnóstico das prostatopatias caninas, assim como observar os resultados obtidos por outros autores a respeito dos métodos abordados, para que se possa verificar a viabilidade da utilização desses métodos de diagnóstico na rotina de clínicos veterinários.

Anatomia e fisiologia da próstata canina

A próstata é a única glândula sexual acessória no cão e possui características funcionais e morfológicas semelhantes a do homem. A glândula prostática desenvolve-se a partir da sexta semana de gestação e possui um formato semioval ao corte transversal. O septo mediano na face dorsal divide a glândula em dois lobos, um direito e um esquerdo. Cada lobo é dividido em lóbulos, que consistem em uma numerosa composição de glândulas tubuloalveolares (EVANS \& CHRISTENSEN, 1993; BARSANTI \& FINCO, 1995; LEROY \& NORTHRUP, 2009).

Localiza-se predominantemente no espaço retroperitonial, caudal à bexiga, na região do trígono vesical, envolvendo a uretra proximal. Possui contato dorsalmente com o reto e ventralmente com a sínfise púbica e com a parede abdominal ventral. Após a perda do úraco remanescente (até os dois meses de idade) uma pequena porção prostática reside na pelve. Com o avançar da idade, a glândula tende a se localizar no abdômen, limitada à cavidade pélvica até aproximadamente os quatro meses de idade e totalmente dentro do abdômen a partir dos dez meses de idade. A próstata é um órgão andrógeno dependente e a castração em qualquer idade resulta em marcada redução em seu tamanho (EVANS \& CHRISTENSEN, 1993; BOOTHE, 1994; BARSANTI \& FINCO, 1995).

Vários fatores podem influenciar no tamanho da próstata, como: idade, raça e peso do animal (GUIDO, 2004). Com a idade, ocorre um aumento do volume prostático, paralelamente à incidência de hiperplasia prostática benigna (BRENDLER et al., 1983).

A função da próstata é produzir fluido prostático para transporte e suporte para os espermatozóides durante a ejaculação (BARSANTI \& FINCO, 1995). Sua secreção possui citrato, lactato, colesterol e enzimas, sendo esta a única que não possui açúcares quando comparada à glândula sexual acessória de outras espécies. O fluido prostático canino é caracterizado pela presença de uma enzima proteolítica, a esterase específica prostática canina, andrógeno dependente, que constitui a maior fração solúvel do tecido prostático e está presente em mais de noventa por cento do total protéico desse fluido (ISAACS \& SHAPER, 1983).

\section{Doenças prostáticas}

As afecções prostáticas mais comuns que acometem os cães são a hiperplasia prostática benigna, prostatite, cistos e neoplasia prostática (SMITH, 2008; JONHSTON et al. 2000). Os sinais mais comuns nas prostatopatias caninas incluem tenesmo, gotejamento de sangue independentemente da micção, hematúria e infecções recorrentes do trato urinário. $\mathrm{O}$ tenesmo pode ser causado pelo aumento da próstata que comprime o reto no canal pélvico. Sinais inespecíficos como febre, indisposição e dor abdominal caudal estão presentes em animais com infecções bacterianas e neoplasia da próstata (BARSANTI \& FINCO, 1995; JOHNSTON et al., 2000; NELSON \& COUTO, 2006;).

A HPB acomete a maioria dos machos não castrados com mais de seis anos de idade. Nos cães, predomina a hiperplasia uniforme e epitelial, enquanto que no homem esta é frequentemente estromal e nodular. Entretanto, apesar da diferença histológica, o curso da doença é similar nas duas espécies (BARSANTI \& FINCO, 1995; NELSON \& COUTO, 2006).

O estrógeno apresenta-se diminuído nos animais com HPB em relação àqueles com histologia normal e os valores séricos desse hormônio oscilam em função do tipo de hiperplasia, sendo menores nas epiteliais e maiores nas complexas. Com isso, é possível estabelecer uma relação direta entre o diagnóstico histológico, a idade do animal e o nível sérico de estrógeno (DE MOURA et al., 2006).

As causas de hiperplasia incluem desequilíbrio na relação de estrógenos e andrógenos, 
aumentando o número de receptores androgênicos e a sensibilidade tecidual aos andrógenos. A diidrotestosterona é o principal andrógeno que promove a HPB. Esse hormônio acumula-se na glândula e tem função de mediador hormonal para a hiperplasia, sendo que esse acúmulo provavelmente ocorre, em parte, devido à diminuição do catabolismo molecular e, em parte, ao aumento da ligação intracelular das moléculas. O processo é acelerado pelo estrógeno, que aumenta o nível de receptores de androgênio na próstata. $\mathrm{O}$ aumento desses receptores permite que mediadores de androgênio cresçam, mesmo com o declínio deste hormônio na idade avançada (WILSON, 1980; KAY, 1994). AHPB pode ser subclínica, ou resultar em sinais como tenesmo e hemorragia prostática, que é observada pelo gotejamento sanguíneo uretral, na ausência de micção, ou em hematúria (NELSON \& COUTO, 2006).

A metaplasia escamosa caracteriza-se pela transformação do epitélio glandular prostático em epitélio escamoso estratificado, no qual a queratina é depositada no interior do lúmen. Geralmente, está associada à prostatite crônica, irritação crônica por cálculos, ao estímulo prolongado por estrógenos endógenos, como tumores de células de Sertoli ou exógenos. Em casos avançados, os ácinos transformam-se em massas sólidas e císticas de epitélio escamoso bem diferenciado (JUBB et al.,I993; JONES et al., 2000).

Os cistos prostáticos ocorrem geralmente em cães idosos e são definidos como lesões cavitárias com parede definida, contendo fluido claro ou turvo em seu interior. (GUIDO, 2004). RAWLINGS et al. (1997) estudaram a prevalência de alteração cística prostática em um grupo de cães e cistos prostáticos foram observados em aproximadamente $14 \%$ desses animais, sendo comum o crescimento bacteriano positivo associado. Cistos paraprostáticos são originários dos ductos millerianos ou decorrentes de cistos de retenção. São adjacentes e juntos à próstata e raramente se comunicam com o parênquima. Esses cistos são frequentemente grandes, estendendo-se à fossa perineal do abdômen (FOSSUM et al., 2002; NELSON \& COUTO, 2006).

As causas associadas à infecção bacteriana da próstata incluem HPB, neoplasia, infecção ascendente do trato urinário ou septicemia, alteração da secreção prostática e disfunção do sistema imunológico. Entretanto, infecções descendentes do trato urinário ou extensão de doenças testiculares e epididimais não são comuns. Deve-se fazer cultura para identificar o microorganismo (KAY, 1994; MATTOON \& NYLAND, 2002). A prostatite sem envolvimento bacteriano vem sendo relatada em cães e seus sinais clínicos são semelhantes aos da prostatite aguda bacteriana. Abscessos prostáticos são consequência de prostatite bacteriana quando ocorre obstrução do ducto excretor. Um cisto pré-existente pode se tornar abscesso quando é contaminado secundariamente (KAY, 1994).

Além dos seres humanos, os cães são os únicos que desenvolvem câncer prostático espontaneamente, porém este é relativamente raro, quando comparado com as outras formas de prostatopatia canina e ao câncer prostático humano. Os animais que apresentam a doença em estágio avançado não respondem à terapia com privação androgênica. Cirurgia, quimioterapia e radioterapia vêm sendo utilizadas para o tratamento, mas o sucesso é limitado, especialmente pela natureza agressiva da doença. Acredita-se que cães com ocorrência natural de câncer prostático são modelos relevantes para estudos da doença em humanos e terapias em cães podem beneficiar tanto estes quanto os homens. (LEROY et al., 2007; LEROY \& NORTHRUP, 2009).

$\mathrm{O}$ adenocarcinoma prostático é a neoplasia mais comum da próstata canina. Ocorre em cães idosos, com média de idade de 10 anos e pode provocar lesões metastáticas na pelve e vértebras lombares (KAY, 1994; NELSON \& COUTO, 2006). Não existe predisposição racial para o desenvolvimento de neoplasias da próstata. Há alta prevalência da doença em cães machos castrados, que pode se desenvolver em um tempo variável após a castração, mas na mesma idade que em cães não castrados, o que sugere que a castração não é um fator inibidor do câncer prostático (TESKE et al., 2002).

De acordo com CORNELL et al. (2000), em uma análise de 76 casos de carcinoma prostático, a maioria dos animais que apresentavam a doença era de médio a grande porte, com uma média de peso corporal de 20,5kg. Trinta e sete por cento dos animais não eram castrados no momento do diagnóstico da neoplasia. Entre os castrados que desenvolveram a doença, a média de idade da castração era de cinco anos e, nesses cães, a neoplasia foi diagnosticada, em média, sete anos após a cirurgia. Ainda observou-se que cães não castrados possuem maior predisposição a desenvolver adenocarcinoma do que animais castrados precocemente, antes dos 12 meses de idade, e oitenta por cento dos animais possuíam metástases no momento da necropsia, sendo elas em linfonodos (39 casos), pulmões (38 casos) e ossos (17 casos). Outros locais de metástases incluíam fígado, cólon, rins, coração, adrenal, cérebro e baço. 
Métodos de diagnóstico das prostatopatias

O exame físico da próstata é realizado por palpações abdominal e retal, que são realizadas para avaliar o tamanho, o formato, a simetria, a consistência e a mobilidade da próstata, bem como para detectar dor ou qualquer desconforto. É necessário o exame radiográfico do abdômen, ultrassonografia, exames citológicos da próstata, cultura bacteriana, biópsia ou uma combinação desses exames para diferenciar os distúrbios prostáticos (NELSON \& COUTO, 2006).

O método ultrassonográfico, transabdominal, constitui-se em referencial seguro na estimativa do tamanho e do crescimento da próstata. Em termos práticos, a ultrassonografia é uma importante ferramenta para a avaliação da progressão ou regressão das doenças prostáticas em resposta aos tratamentos empregados, podendo até ser realizada estimativa aproximada do peso e do volume da glândula. Através desse exame, é possível diferenciar as prostatomegalias identificadas por exames radiográficos, cujas lesões visualizadas não são específicas. $\mathrm{O}$ exame transretal, usado como rotina em estudos reprodutivos em grandes animais, ainda não é utilizado com frequência em cães. A vantagem da varredura transretal é o aumento da qualidade da imagem, devido à ausência de estruturas anatômicas sobrepostas e à habilidade de otimizar a área focal. As desvantagens na prática em pequenos animais são a inconveniência, o desconforto do paciente e a eventual necessidade de sedação ou anestesia (FEENEY et al., 1987; MATTOON \& NYLAND, 2002; CRUZEIRO et al., 2008).

A massagem prostática é um procedimento para a coleta de fluido prostático. Inicialmente, ocorre a introdução de uma sonda uretral na bexiga, para a retirada da urina, e então se coloca a sonda na altura da próstata para que se possa coletar o material. A próstata é massageada por via retal e o material é aspirado através da sonda (NELSON \& COUTO, 2006).

A aspiração por agulha fina ou a biópsia da próstata, ou ambas, podem ser necessárias para o diagnóstico. A aspiração com agulha fina é realizada para a obtenção de amostras para os exames citológicos e microbiológicos. É realizada por via percutânea e preferencialmente orientada por equipamento de ultrassom, sendo segura e simples. Biópsias da próstata podem ser realizadas com agulhas Tru-Cut ou com uma retirada cirúrgica, em cunha do tecido prostático de um dos lobos. Todas as biópsias devem ser submetidas a exame histopatológico (KUSTRITZ, 2006).

Em um estudo, BOLAND et al. (2003) realizaram drenagem guiada por ultrassom de cistos e abscessos prostáticos em cães. Em oito dos trinta animais avaliados, foram diagnosticados abscessos prostáticos e em cinco encontrou-se cistos prostáticos.
O diagnóstico foi baseado na citopatologia e na cultura bacteriana. Foi instituída antibioticoterapia por quatro semanas e os animais foram castrados após o procedimento de drenagem. Os pacientes foram novamente examinados ultrassonograficamente e os cistos residuais drenados. Não foram observadas complicações clínicas após o procedimento e os sinais clínicos se resolveram em todos os animais.

Marcadores bioquímicos

Substâncias biológicas séricas e seminais que são produzidas tanto por tecidos normais quanto alterados podem ser utilizadas para diagnosticar condições patológicas, sendo reconhecidas como biomarcadores. No cão, o biomarcador de doença prostática de maior relevância é a esterase específica prostática canina (CPSE). Em humanos, os mais utilizados são o antígeno prostático específico (PSA) e a fosfatase ácida (PAP), porém a utilização desses marcadores em cães ainda é controversa, assim, na medicina veterinária, os biomarcadores prostáticos séricos ainda não são utilizados na rotina. Já na medicina humana, devido ao maior conhecimento e a sua comprovada utilidade na detecção das alterações prostáticas, esses são amplamente utilizados na rotina diagnóstica das enfermidades desta glândula (GOBELLO et al., 2002).

O uso de marcadores teciduais pode auxiliar no diagnóstico precoce de enfermidades graves, como o adenocarcinoma, além de evitar biópsias desnecessárias. Análises proteômicas revelam que apesar de a maioria das proteínas que são expressas por carcinomas prostáticos caninos serem também expressas em próstatas normais, os carcinomas possuem componentes protéicos exclusivos que permitem sua separação de tecidos normais. Atualmente, a PAP é o marcador com maior potencial para o uso prático em cães, contudo, estudos adicionais devem ser realizados para estimar o seu valor clínico. $\mathrm{O}$ antígeno prostático específico está disponível em laboratórios humanos e apresenta custo significantemente elevado, além de existirem dúvidas sobre a secreção desta proteína pela próstata canina. A esterase específica prostática canina ainda não está disponível em forma de teste laboratorial (SOUZA \& TONIOLLO; 2001; LEROY et al., 2007).

Como na próstata humana, a secreção da PAP no cão é dependente de hormônio e apresenta considerável variação com a idade. Estudos, como o de CORAZZA et al. (1994), têm demonstrado resultados promissores na utilização da PAP como marcador bioquímico de adenocarcinoma canino pelo significado clínico no diagnóstico precoce do tumor local, na 
diferenciação entre adenocarcinoma prostático e HPB e no acompanhamento da eficácia terapêutica contra o câncer. Os resultados obtidos demonstraram que, nos machos com próstata normal, a concentração sérica dessa enzima aumentou significativamente com a idade. Já cães que apresentavam HPB apresentaram menor elevação nos níveis séricos médios de PAP do que aqueles com adenocarcinoma prostático. Da mesma forma, De MOURA et al. (2006) destacam o aumento sérico e urinário dessa glicoproteína em função do tipo de hiperplasia, especialmente da forma complexa, apesar de não terem observado diferença estatística nas concentrações sérica e urinária de PAP entre animais com próstata normal e hiperplásica. De outra parte, BELL et al. (1995) relatam que este marcador não foi significativamente diferencial em cães com HPB, prostatites e carcinomas prostáticos.

O PSA é uma glicoproteína produzida pelo tecido prostático. Desde 1994, é utilizado como um marcador para diagnóstico de tumores prostáticos da espécie humana e auxilia no monitoramento de tratamentos, particularmente após prostatectomia. Sua detecção após prostatectomia radical indica tecido prostático residual ou metástase e o aumento da sua concentração indica doença recorrente (ARMBRUSTER, 1993).

Desde a identificação do PSA, contínuos avanços tecnológicos vêm promovendo exames altamente sensíveis para a sua quantificação. $O$ valor positivo da sua determinação para estimativa de risco para o câncer faz desse marcador o mais utilizado para o monitoramento da progressão e resposta ao tratamento de pacientes humanos com câncer de próstata. A detecção tumoral precoce através da dosagem dos níveis dessa enzima tem sido utilizada como um caminho para diminuir a mortalidade por câncer prostático. A sua identificação na análise sanguínea pode estar relacionada a uma informação sobre o prognóstico e o uso de exames ultrassensíveis, além de poder permitir uma detecção precoce do tumor (ABLIN, 1997). Em um estudo com cães realizado por DE MOURA et al. (2006), o PSA sérico apresentou menor concentração em animais com próstata normal em relação aos com hiperplasia epitelial e, de modo geral, aos demais tipos de HPB. Segundo HARVEY et al. (2009), esse marcador é utilizado como um de vários indicadores de biópsia prostática.

Apesar de estudos mostrarem imunorreatividade para o PSA humano em próstatas caninas, tanto normais quanto com câncer (ANIDJAR et al., 2001; AUMULLER et al., 1990; BELL et al., 1995; McENTEE et al., 1987; SORENMO et al., 2003), a presença dessa proteína no plasma e sua utilização para detecção de prostatopatias caninas permaneceu controversa. Diversos estudos foram realizados, porém, não foi possível determinar a presença do PSA por Southern blot (KARR et al., 1995) ou PCR em tempo real (AGGARWAL et al., 2006).

Entretanto, foi identificada uma proteína denominada esterase específica prostática canina (CPSE). Essa glicoproteína é uma enzima proteolítica e constitui a maior fração de proteína solúvel no tecido prostático de cães (CHAPDELAINE et al., 1983; ISAACS \& COFFEY, 1984). Um estudo comparativo entre PSA e CPSE demonstrou que essas enzimas apresentam homologia. Dessa forma, a imunorreatividade dos anticorpos policlonais anti-PSA humanos utilizados em diversos estudos pode ser atribuída à presença de CPSE no plasma e/ou urina de próstata canina, que apresenta epitopos conservados em relação à PSA (CHAPDELAINE et al., 1991; LAI et al., 2008).

As duas proteínas possuem massas moleculares similares: 29kDa (PSA) e 34kDa (CPSE) e são enzimas relacionadas, pertencentes à classe de serino-proteases. Porém, sua atividade sobre substratos sintéticos demonstrou que a CPSE canina é uma enzima tipo tripsina, enquanto a PSA apresenta atividade do tipo quimotripsina (DUBÉ et al., 1986; GOBELLO et al., 2002). Assim, testes baseados na atividade enzimática da PSA não apresentam aplicabilidade para estudo da próstata canina.

A CPSE apresentou maiores concentrações séricas em cães com HPB quando comparado a cães normais em estudo de BELL e colaboradores (1995), enquanto PSA não foi detectado e PAP não apresentou diferenças significativas entre cães sadios e com prostatopatias como HPB, prostatite bacteriana e carcinoma prostático. A presença de CPSE é órgãoespecífico, podendo ser proveitosa a sua utilização como um marcador da função prostática (ISAACS \& SHAPER, 1983; ISAACS \& COFFEY, 1984; BELL et al., 1995; DUBÉ et al., 1995).

Contudo, deve-se definir ainda a função exata da dosagem da esterase específica prostática canina sérica, que aparenta ser um método diagnóstico promissor em doenças prostáticas caninas nãoneoplásicas (GOBELLO et al., 2002).

\section{CONCLUSÃO}

As doenças prostáticas em cães merecem atenção na clínica veterinária por serem alterações bastante frequentes. Os sinais clínicos das diferentes doenças que acometem a próstata canina são inespecíficos e métodos de diagnóstico complementares 
são necessários para que se possa fazer um diagnóstico preciso. Através do exame ultrassonográfico, consegue-se estimar o tamanho da próstata e as condições do parênquima, enquanto que, pelo exame citológico ou biópsia, pode-se realizar um estudo celular detalhado para diferenciar as possíveis causas da doença, porém esses métodos de diagnóstico não oferecem um resultado precoce, o que muitas vezes compromete o prognóstico. $\mathrm{O}$ uso de biomarcadores prostáticos ainda não é uma realidade na medicina veterinária, pois até o momento não existem testes de rotina que detectem a doença prostática precocemente, especialmente a HPB e o câncer, o que poderia evitar as complicações clínicas nos pacientes acometidos.

\section{REFERÊNCIAS}

ABLIN, R.J. A retrospective and prospective overview of prostate-specific antigen. Journal of Cancer Research in Clinical Oncology, v.123, p.583-594, 1997. Disponível em: $<$ http://www.springerlink.com/content/qlqtn8ryvy18656x/>. Acesso em: 08 nov. 2009. doi: 10.1007/s004320050110.

ANIDJAR, M. et al. In vivo model mimicking natural history of dog prostate cancer using DPC-1, a new canine prostate carcinoma cell line. Prostate, v.46, p.2-10, 2001.

ARMBRUSTER, D.A. Prostate-specific antigen: biochemistry, analytical methods, and clinical application. Clinical Chemestry, v.39, p.181-195, 1993.

AUMULLER, G. et al. Species and organ-specificity of secretory proteins derived from human prostate and seminal vesicles. Prostate, v.17, p.31-40, 1990.

BARSANTI J.A., FINCO D.R. Prostatic diseases. In: ETTINGER S.J.; FELDMAN E.C. Textbook of veterinary internal medicine. Philadelphia: Saunders, 1995. V.2, cap.128, p.1662-1685.

BARSANTI J.A. et al. Evaluation of diagnostic techniques for canine prostatic diseases. Journal of the American Veterinary Medical Association, v.177, p.160-163, 1980.

BELL, F.W. et al. Evaluation of serum and seminal plasma markers in the diagnosis of canine prostatic disorders. Journal of Veterinary Internal Medicine, v.9, p.149-153, 1995.

BOLAND, L.E. et al. Utrasound guided percutaneous drainage as the primary treatment for prostatic abscesses and cysts in dogs. United Kingdom Journal of the American Animal Hospital Association, v.2. p.151-159, 2003.

BOOTHE, H.W. Surgery of the prostate gland. In: BICHARD, S.J.; SHERDING, R.G. Saunders manual of small animal practice. Philadelphia: Saunders, 1994. p.872-876.

BRENDLER, C.B. et al. Spontaneous benign prostatic hyperplasia in the Beagle age-associated changes in serum hormone levels, and the morphology and secretory function of the canine prostate. Journal of clinic investigation, v.71, p.1114-1123, 1983.
CARTEE, R.E.; ROWLES, T. Transabdominal sonographic evaluation of the canine prostate. Veterinary Radiology, v.24, n.4, p.156-164, 1983.

CHAPDELAINE, P. et al. Characterization and expression of the prostatic arginine esterase gene, a canine glandular kallikrein. DNA and Cell Biology, v.10, p.49-59, 1991.

CORAZZA, M. et al. Serum total prostatic and non-prostatic acid phosphatase in healthy dogs and in dogs with prostatic diseases. Journal of Small Animal Practice, v.35, n.5, p.307-310, 1994.

CORNELL, K.K. et al. Clinical and pathologic aspects of spontaneous canine prostate carcinoma: a retrospective analysis of 76 cases. Prostate, v.45, p.173-183, 2000.

CRUZEIRO, R.S. et al. Determinação das mensurações prostáticas de cães pela ultra-sonografia transabdominal. Revista Ceres, v.55, p.461-466, 2008.

DE MOURA, V.M.B.D. et al. Mensuração de hormônios andrógenos, estrógeno, fosfatase ácida prostática (PAP) e antígeno prostático específico (PSA) em cães adultos com próstata normal e hiperplásica. Brazilian Journal of Veterinary Research and Animal Science, v.43, n.1, p.6573, 2006.

DI SANTIS, G.W. et al. Aspectos clínicos e morfológicos das alterações prostáticas em cães - revisão. Revista de Educação Continuada do CRMV-SP, v.4, f.2, p.46-52, 2001.

DUBÉ J.Y. et al. Dog prostate arginine esterase is related to human prostate specific antigen. Clinical \& Investigative Medicine v.9, p.51-54, 1986.

DUBÉ, J.Y. et al. Search for androgen response elements in the proximal promoter of the canine prostate arginine esterase gene. Journal of Andrology, v.16, p.304-311, 1995.

EVANS H.E.; CHRISTENSEN G.C. The urogenital system. In: Miller's anatomy of the dog. Philadelphia: Saunders; 1993. p.514-516.

FEENEY, D.A. et al. Canine prostatic disease - comparison of ultrasonographic appearance with morphologic and microbiologic findings: 30 cases (1981-1985). Journal of American Veterinary Medical Association, v.190, n.8, p.1027-1034, 1987.

FOSSUM, T.W. et al. Outras doenças ósseas e articulares. In: FOSSUM, T.W. Cirurgia de pequenos animais. São Paulo: Rocca, 2002. p.1114-1136.

GOBELLO, C. et al. Serum and seminal markers in the diagnosis of disorders of the genital tract of the dog: a mini-review. Theriogenology, v.57, p.1285-1291, 2002.

GUIDO, M.C. Utra-sonografia do aparelho reprodutor masculino. In: CARVALHO, C.F. Ultra-sonografia em pequenos animais. São Paulo: Rocca, 2004. p.213-223.

HARVEY, P. et al. Systematic review of the diagnostic accuracy of prostate specific antigen. BMC Urology, v.9, p.9-14, 2009.

ISAACS, W.B.; SHAPER, J.H. Isolation and characterization of the major androgen-dependent glycoprotein of canine 
prostatic fluid. Journal of Biological Chemistry, v.258, n.10, p.6610-6615, 1983.

ISAACS, W.B.; COFFEY, D.S. The predominant protein of canine seminal plasma is an enzyme. Journal of Biological Chemistry, v.259, n.18, p.11520-11526, 1984.

JOHNSTON, S.D. et al. Prostatic disorders in the dog. Animal Reproduction Science, v.2, p.405-415, 2000.

JONES, T.C. et al. Sistema genital. In: Patologia veterinária. 6.ed. São Paulo: Manole, 2000. p.1237-1240.

JUBB, K.V.F. et al. Male genital system. In: FOSTER, R.A. Pathology of the domestic animais. 4.ed. San Diego: Academic, 1993. V.3, p.523-529, 1993.

KAY, N.D. et al. Cytological diagnosis of canine prostatic disease using a urethral brush techinique. Journal of the American Animal Hospital Association, v.25, p.517-526, 1989.

KAY, N.D. Disease of the prostate gland. In: BIRCHARD, J.; SHERDING, E.R.G. Manual of small animal practice. Philadélphia: Saunders, 1994. p.856-871.

KARR, J.F. et al. The presence of prostatic-specific antigenrelated genes in primates and the expression of recombinant human prostate specific antigen in a transfected murine cell line. Cancer Research, v.55, p.2453-2462, 1995.

KUSTRITZ, M.V.R. Collection of tissue and culture samples from the canine reproductive tract. Theriogenology, v.66, p.567-574, 2006.

LAI, C.L. et al. Histopathological and immunohistochemical characterization of canine prostate cancer. Prostate, v.68, p.477-488, 2008.

LEROY, B.E.; NORTHRUP, N. Prostate cancer in dogs: comparative and clinical aspects. Veterinary Journal, v.180, p.149-162, 2009.

LEROY, B. et al. Protein expression profiling of normal and neoplastic canine prostate and bladder tissue. Veterinary and Comparative Oncology, v.5, p.119-130, 2007. Disponível em: <http://onlinelibrary.wiley.com/doi/10.1111/ j.1476-5829.2006.00121.x/full>. Acesso em: 18/12/2009 doi: 10.1111/j.1476-5829.2006.00121.x.
MATTOON, J.S.; NYLAND, T.G. Small animal diagnostic ultrasound. São Paulo: Rocca, 2002. p.250-266.

MCENTEE, M. et al. Adenocarcinoma of the canine prostate: Immunohistochemical examination for secretory antigens. Prostate, v.11, p.163-170, 1987.

NELSON, R.W.; COUTO G. Distúrbios da próstata. In: Medicina interna de pequenos animais. Rio de Janeiro: Guanabara Koogan, 2006. p.893-899.

RAWLINGS, C.A. et al. Use of prostatectomy for treatment of prostatic abcesses and cysts in dogs. Journal of the American Veterinary Medical Association, v.7, p.868-871, 1997.

SERAKIDES, R. et al. Carcinoma de próstata com metástase óssea em cão. Arquivo Brasileiro de Medicina Veterinária e Zootecnia, v.49, n.3, p.385-388, 1997.

SMITH, J. Canine prostatic disease: a review of anatomy, pathology, diagnosis, and treatment. Theriogenology, v.70, p.375-383, 2008.

SORENMO, K.U. et al. Immunohistochemical characterization of canine prostatic carcinoma and correlation with castration status and castrationtime. Veterinary and Comparative Oncology, v.1, p.48-56, 2003.

SOUZA, F.F.; TONIOLLO, G.H. Marcadores de tecido prostático no cão. Revista de Educação Continuada CRMV-SP, v.4, f.3, p.63-70, 2001. Disponível em: <http://www.hostcentral.com.br/ crmv/PDF/v4n3a08.pdf>. Acesso em: 15 set. 2009.

TESKE, E. et al. Canine prostate carcinoma: epidemiological evidence of an increased risk in castrated dogs. Molecular and Cellular Endocrinology, v.197, p.251-255, 2002.

WATERS, D.J.; BOSTWICK, D.G. The canine prostate is a spontaneous model of intraepithelial neoplasia and prostate cancer progression. Anticancer research, v.1, n.17, p.14671470, 1997.

WEAVER, A.D. Fifteen cases of prostatic carcinoma in the dog. Veterinary Record, v.1, n.109, p.71-75, 1981.

WILSON, J.D. The pathogenesis of benign prostatic hyperplasia. American Journal of Medicine, v.68, n.5, p.745-756, 1980. 